Research article

Open Access

\title{
NOS2 polymorphisms associated with the susceptibility to pulmonary arterial hypertension with systemic sclerosis: contribution to the transcriptional activity
}

\author{
Yasushi Kawaguchi1, Akiko Tochimoto1, Masako Hara1, Manabu Kawamoto1, Tomoko Sugiura1, \\ Yasuhiro Katsumata ${ }^{1}$, Jun Okada ${ }^{2}$, Hirobumi Kondo ${ }^{2}$, Mitsuo Okubo ${ }^{3}$ and Naoyuki Kamatani ${ }^{1}$
}

\author{
1Institute of Rheumatology, Tokyo Women's Medical University, Tokyo, Japan \\ 2Department of Internal Medicine, Kitasato University School of Medicine, Sagamihara, Japan \\ ${ }^{3}$ Transfusion Medicine and Cell Therapy, Saitama Medical School, Kawagoe, Japan \\ Corresponding author: Yasushi Kawaguchi, y-kawa@ior.twmu.ac.jp
}

Received: 22 Feb 2006 Revisions requested: 27 Apr 2006 Revisions received: 14 May 2006 Accepted: 2 Jun 2006 Published: 3 Jul 2006

Arthritis Research \& Therapy 2006, 8:R104 (doi:10.1186/ar1984)

This article is online at: http://arthritis-research.com/content/8/4/R104

(c) 2006 Kawaguchi et al.; licensee BioMed Central Ltd.

This is an open access article distributed under the terms of the Creative Commons Attribution License (http://creativecommons.org/licenses/by/2.0), which permits unrestricted use, distribution, and reproduction in any medium, provided the original work is properly cited.

\begin{abstract}
Systemic sclerosis (SSc) is a connective tissue disease characterized by tissue fibrosis. One of several complications of $\mathrm{SSc}$, pulmonary arterial hypertension $(\mathrm{PAH})$ can be refractory to treatment, both novel and established. In the present study we investigated the ratio of circulating nitric oxide to endothelin-1 in patients with both SSc and $\mathrm{PAH}$, and determined whether polymorphisms in NOS2 (the nitric oxide synthase 2 gene) are associated with susceptibility to $\mathrm{PAH}$. Endothelin-1 in plasma and nitric oxide metabolites (nitrate and nitrite) in serum were measured. The nitric oxide/endothelin-1 ratio was significantly lower in patients with both SSc and PAH than in patients with SSc only or in healthy control individuals. We confirmed the presence of two single nucleotide polymorphisms at positions 1,026 and -277 and a pentanucleotide repeat (CCTTT) at -2.5
\end{abstract}

kilobases. There were significant differences in single nucleotide polymorphisms between patients with SSc who had $\mathrm{PAH}$ and those who did not, and between patients with both SSc and PAH and healthy control individuals. The CCTTT repeat was significantly shorter in patients with both SSc and $\mathrm{PAH}$ than in patients with SSc only or in healthy control individuals. Transcriptional activity were analyzed using the luciferase reporter assay. The transcriptional activity of NOS2 was much greater in fibroblasts transfected by a vector with a long allele of the CCTTT repeat than in those transfected by a vector with a short allele. Polymorphisms in the NOS2 gene are associated with transcriptional activity of the NOS2 gene and with susceptibility to SSc-related PAH.

\section{Introduction}

Systemic sclerosis (SSc) is an autoimmune disease of unknown aetiology that is characterized by extensive fibrosis of skin and visceral organs, and dysfunction of vascular tone [1]. In its more severe forms, cardiac involvement and respiratory involvement are the most significant determinants of outcome [2]. In particular, pulmonary hypertension is a fatal complication in both diffuse and limited cutaneous SSc [3]. Pulmonary hypertension is generally divided into four major categories: pulmonary arterial hypertension (PAH), pulmonary hypertension associated with left-sided heart disease, pulmonary hypertension associated with lung disease or hypoxae- mia, and pulmonary hypertension due to chronic thrombotic or embolic disease [4]. A major part of pulmonary hypertension as it pertains to SSc corresponds with the pathophysiology of $\mathrm{PAH}$, a disease of the small pulmonary arteries characterized by vascular proliferation, vasoconstriction, remodelling of the pulmonary vessel wall and thrombosis in vessels.

Vasodilators such as nitric oxide (NO) and prostacyclin, along with prolonged overexpression of vasoconstrictors such as endothelin (ET)-1, not only affect vascular tone but also promote vascular remodelling, both of which have been implicated in the pathogenesis of PAH [5-12]. Previous studies

$\mathrm{bp}=$ base pairs; DMEM = Dulbecco's modified Eagle's medium; ET = endothelin; FBS = foetal bovine serum; NO = nitric oxide; NOS = nitric oxide synthase; $\mathrm{PAH}=$ pulmonary arterial hypertension; $\mathrm{PCR}=$ polymerase chain reaction; $\mathrm{PPH}=$ primary pulmonary hypertension; SNP = single nucleotide polymorphism; SSc = systemic sclerosis. 
identified high levels of ET-1 in the plasma of patients with SSc, especially in those with SSc complicated by $\mathrm{PAH}$ $[13,14]$. However, reported levels of circulating NO in patients with SSc are inconsistent, with several studies [15-18] finding increased levels of $\mathrm{NO}$ in patients with SSc and others $[19,20]$ finding low levels, similar to those in healthy individuals. In our previous study [21] NO levels were markedly elevated in patients with early-stage diffuse cutaneous SSc, especially when the SSc was accompanied by active alveolitis, but concentrations of NO in serum were low in late-stage limited cutaneous SSc. No patients suffered the complication of PAH in that study. Characteristic levels of NO and NO/ET1 ratio in patients with both $\mathrm{SSc}$ and $\mathrm{PAH}$ remain to be established.

$\mathrm{NO}$ is an endothelial-derived relaxing factor that is synthesized from L-arginine by nitric oxide synthase (NOS) [22]. Three isoforms of NOS have been identified [23]: NOS-1 (neuronal NOS), NOS-2 (inducible NOS) and NOS-3 (endothelial NOS). NOS-2 is the major source of NO production in conditions involving exposure to cytokines; this is because it is induced by a variety of cell types, including the proinflammatory cytokines interleukin-1, tumour necrosis factor- $\alpha$, interferon- $\gamma$, and ET-1 [24].

Two randomized, double-blind, placebo-controlled trials $[25,26]$ evaluated the efficacy of the ET receptor antagonist bosentan in patients with PAH that was either primary or associated with SSc. Another therapeutic strategy in $\mathrm{PAH}$ is to increase the activity of endogenous $\mathrm{NO}$, which enhances NOdependent cGMP-mediated pulmonary vasodilatation through inhibition of the breakdown of cGMP by phosphodiesterase type 5 [27]. Although long-term inhaled NO therapy has shown only a small benefit in patients with $\mathrm{PAH}$ [28], phosphodiesterase type 5 inhibitors (for example, sildenafil) have been found to improve pulmonary artery pressure in patients with PAH [29].

Because these novel therapies were developed to prolong survival and improve patients' quality of life, we speculate that an imbalance between ET-1 and NO is key to the pathogenesis of SSc complicated by PAH. Polymorphisms in the NOS2 gene promoter are thought to regulate its transcription activity, which is reportedly associated with susceptibility to type 1 diabetes [30] and atopy [31] and with protection against malaria [32]. In the present study we determined the levels of ET-1 and $\mathrm{NO}$ in blood from patients with SSc with or without $\mathrm{PAH}$, and we investigated the association between gene polymorphisms in NOS2 and susceptibility to PAH.

\section{Materials and methods Study patients}

Twenty patients with SSc complicated by PAH were recruited. All had been admitted to Aoyama Hospital of Tokyo Women's Medical University or Kitasato University Hospital. As a dis- ease control group, 58 patients with SSc but not PAH were selected from patients admitted to Aoyama Hospital. Detailed clinical characteristics of all patients are shown in Table 1. All patients with SSc were of Japanese origin, met the criteria established by the American College of Rheumatology for SSc [33], and were classified as having either diffuse or limited cutaneous SSc according to the classification proposed by LeRoy and coworkers [34]. Ninety-five DNA samples were obtained from healthy volunteers who were unrelated individuals of Japanese origin. All DNA samples were collected, with approvals granted by the appropriate ethical committees of Tokyo Women's Medical University, Kitasato University School of Medicine, and Saitama Medical School.

We identified the presence of a complication of $\mathrm{PAH}$ in the following manner. All patients with SSc were first evaluated by Doppler echocardiography, and then cardiac catheterization was performed when right ventricular systolic pressure was greater than $30 \mathrm{mmHg}$, based on Doppler echocardiography. $\mathrm{PAH}$ was diagnosed in patients with SSc who satisfied the modified US National Institutes of Health criteria for PAH after cardiac catheterization [35], specifically mean pulmonary artery pressure above $25 \mathrm{mmHg}$ at rest or $30 \mathrm{mmHg}$ after exercise, with normal pulmonary artery wedge pressure. The complication of pulmonary fibrosis was identified using highresolution computed tomography of the chest. Patients with the following complications were excluded: severe pulmonary fibrosis, with functional vital capacity below 70\%; left-sided heart disease; chronic thrombotic or embolic disease; renal failure, including a history of scleroderma renal crisis; hypertension; and diabetes.

\section{Measurement of plasma endothelin-1 and serum nitric oxide levels}

Blood samples were obtained from 16 patients with both SSc and $\mathrm{PAH}$ and from 26 patients with SSc without $\mathrm{PAH}$ who were randomly selected from among patients with SSc who donated DNA samples at the time of admission to Aoyama Hospital with informed consent. No specific diet was given to patients while they were hospitalized. Twenty healthy volunteers (normal control individuals) who had no history of dieting or smoking gave informed consent to participate in the study and gave blood samples. ET-1 levels were measured in plasma using an enzyme-linked immunosorbent assay kit (R\&D Systems, Cambridge, MA, USA). Because serum NO is quickly degraded into nitrite and nitrate, we measured the total levels of these NO metabolites as indicators of NO level, using a calorimetric assay kit (Cayman Chemical, Ann Arbor, MI, USA).

\section{Sequencing the NOS2 promoter region}

Genomic DNA was extracted from the blood sample using a DNA extraction kit (Qiagen, Valencia, CA, USA). For direct sequencing, PCR was performed to amplify the promoter region of the NOS2 gene from -100 to $-1,335 \mathrm{bp}$. The forward 
Table 1

\begin{tabular}{|c|c|c|c|}
\hline \multirow[t]{2}{*}{ Characteristic } & \multicolumn{2}{|l|}{ SSc patients } & \multirow[t]{2}{*}{ Healthy controls } \\
\hline & With $\mathrm{PAH}$ & Without PAH & \\
\hline Number at entry ( $n$ (male:female) & $20(1: 19)$ & $58(5: 53)$ & $95(8: 87)$ \\
\hline Age (years; mean (range) & $48.6(17-80)$ & $47.7(19-77)$ & $40.9(22-78)$ \\
\hline Diffuse SSc:limited SSc $(n)$ & $6: 14$ & 33:25 & \\
\hline Disease duration (months; mean (range) & $42.0(6-130)$ & $41.9(5-120)$ & \\
\hline Pulmonary fibrosis ( $n$ (\%) & $6(30)$ & $31(53)$ & \\
\hline \multicolumn{4}{|l|}{ Frequency of ANA ( $n(\%)$} \\
\hline Anti-U1-snRNP antibody & $11(55)$ & $17(29)$ & 0 \\
\hline Anti-topoisomerase I antibody & $1(5)$ & $13(22)$ & 0 \\
\hline Anti-centromere antibody & $5(25)$ & $12(21)$ & 0 \\
\hline
\end{tabular}

ANA, antinuclear antibody; $\mathrm{PAH}$, pulmonary arterial hypertension; SSc, systemic sclerosis.

Table 2

Distribution of single nucleotide polymorphisms in NOS2 gene promoter region

\begin{tabular}{|c|c|c|c|c|c|c|c|c|c|c|}
\hline \multirow[t]{2}{*}{ Subjects } & \multicolumn{3}{|c|}{$-1,026 b p$} & \multicolumn{3}{|c|}{-277 bp } & \multicolumn{4}{|c|}{ Haplotype } \\
\hline & $\mathrm{G} / \mathrm{G}$ & $\mathrm{G} / \mathrm{T}$ & $\mathrm{T} / \mathrm{T}$ & $\mathrm{A} / \mathrm{A}$ & $A / G$ & $\mathrm{G} / \mathrm{G}$ & $\mathrm{GA}$ & TA & GG & $\mathrm{TG}$ \\
\hline $\begin{array}{l}\text { SSc with } \\
\text { PAH }(n= \\
20)\end{array}$ & $20(100)$ & 0 & 0 & $20(100)$ & 0 & 0 & 40 & 0 & 0 & 0 \\
\hline $\begin{array}{l}\text { SSc } \\
\text { without } \\
\text { PAH }(n= \\
58)\end{array}$ & $43(74)$ & $11(19)$ & $4(7)$ & $43(74)$ & $10(17)$ & $5(9)$ & 96 & 0 & 1 & 19 \\
\hline $\begin{array}{l}\text { Healthy } \\
\text { controls ( } n \\
=95 \text { ) }\end{array}$ & $69(73)$ & $23(24)$ & 3 (3) & 73 (77) & $19(20)$ & 3 (3) & 161 & 0 & 4 & 25 \\
\hline
\end{tabular}

Values indicate number (\%) of genotype or number of haplotype, which consists of two SNPs at $-1,026$ and -277 . There were significant differences between patients with SSc who did and those who did not have PAH in the distribution of two SNPs at -277 and $-1,026$ (both $P=$ 0.04 , by Fisher's exact test). Comparing the distribution of two SNPs between patients with SSc complicated by PAH and healthy control individuals, there was a significant difference at $-1,026(P=0.02)$, but there was no difference at $-277(P=0.053)$. With respect to haplotype, the frequency of GA was significantly higher in SSc with PAH than in SSc without PAH and in healthy control individuals $(P=0.001$ and $P=0.02$, respectively). PAH, pulmonary arterial hypertension; SNP, single nucleotide polymorphism; SSc, systemic sclerosis.

and reverse primers were 5'-TCATCCACACATTCACTCAAC-3' and 5'-CCAAAGGGAGTGTCCCCAGCTT-3', respectively. The sequences of the $P C R$ products were analyzed using the ABI Prism 3100 Sequence Detection System (Applied Biosystems, Foster City, CA, USA).

\section{Haplotype typing in pairs of NOS2 polymorphisms}

We entered the genotype data into the PENHAPLO computer program, developed by Ito and coworkers [36], to estimate haplotype frequency in the population and to calculate the posterior probability of diplotype distribution for each study subject. This program was designed for haplotype typing using a maximum likelihood estimation method based on the expectation maximization algorithm under the assumption of Hardy-Weinberg equilibrium for the population.

\section{Analysis of variable numbers of the CCTTT repeat polymorphism of the NOS2 promoter region}

Genomic DNA was amplified by PCR with the use of a $F A M^{\mathrm{TM}}$ labelled sense primer (5'-ACCCCTGGAAGCCTACAACTGCAT-3') and an antisense primer (5'-GCCACTGCACCCTAGCCTGTCTCA-3'). The various alleles were resolved by capillary electrophoresis on an ABI Prism 3100 Genetic Analyzer System (Applied Biosystems). Allele sizes were calculated using the GeneScan Analysis computer program, with a GeneScan ${ }^{\mathrm{TM}}-500$ ROX $^{\mathrm{TM}}$ size standard (Applied Biosystems) as the internal size standard. 

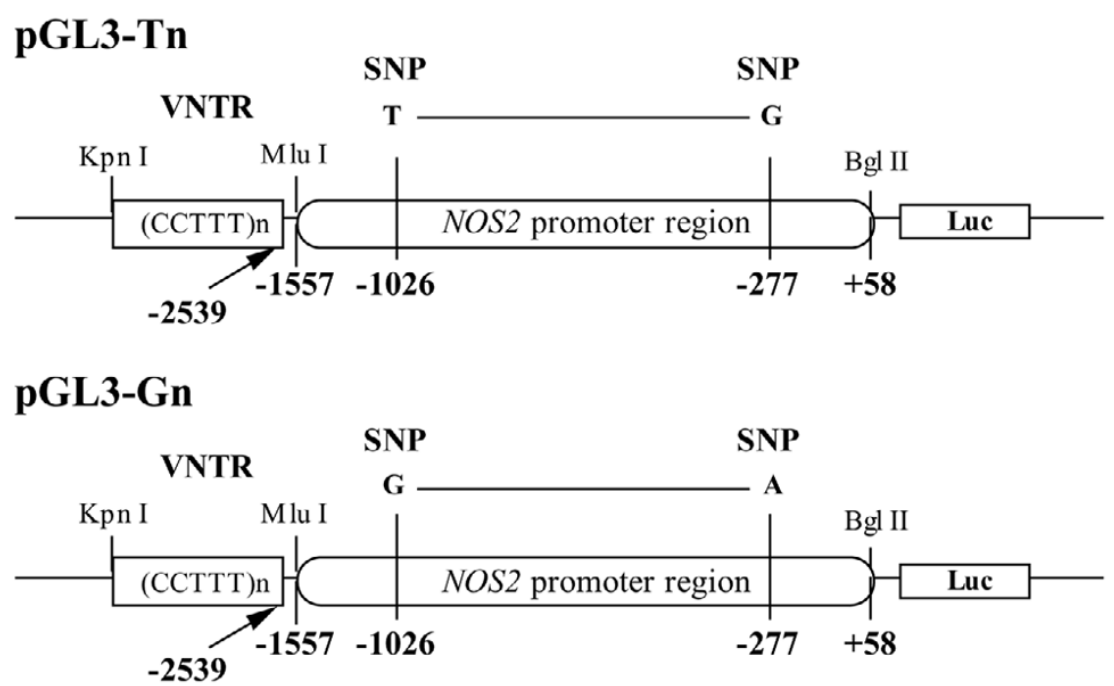

A schematic construct of the promoterless pGL3-basic vector. The luciferase vector ( $p G L 3$ ) was inserted with variable numbers of CCTTT repeats and the $1.5 \mathrm{~kb}$ minimal human NOS2 promoter region $(-1,557$ to $+58 \mathrm{bp}$ ). The promoter region contained either $\mathrm{T}$ or $\mathrm{G}$ at $-1026 \mathrm{bp}$ (referred to as pGL3-T and pGL3-G, respectively). Each vector of pGL3-T and pGL3-G had allele G and allele A at -277 bp, respectively. The 6, 8, 10, 12, and 14 repeats of the pentanucleotide (CCTTT) region were obtained by PCR. The resulting constructs were named pGL3-T6, pGL3-G6, pGL3-T8, pGL3G8, pGL3-T10, pGL3-G10, pGL3-T12, pGL3-G12, pGL3-T14 and pGL3-G14 and contain 6, 8, 10, 12 and 14 repeats, respectively. bp, base pairs; kb, kilobases; SNP, single nucleotide polymorphism; VNTR, variable numbers of tandem repeat.

\section{Analysis of transcriptional activity of NOS2 in human fibroblasts}

The 5 ' flanking region of the NOS2 gene $(-1,557$ to +58$)$ was prepared by PCR using a set of primers. The forward primer (5'-GATTCTGACTCTTTCCCTGAG-3') is located -1,557 bp from the transcription start site, and the reverse primer (5'GGAATGAGGCTGAGTTCTCTGCGGC-3') is located +58 bp from the transcription start site. Genomic DNA containing the T/G allele at $-1026 \mathrm{bp}$ from the transcription start site of the NOS2 gene was used as a PCR template. The PCR product was inserted into a pGL3-Basic Vector (Promega, Madison, WI, USA) that contained the firefly luciferase reporter element, and all constructs were sequenced using the pGL3 forward and reverse sequencing primers. The pGL3 vectors with $\mathrm{T}$ or $\mathrm{G}$ at -1,026 bp are referred to as pGL3-T and pGL3$G$, respectively, as shown in Figure 1. The sequences of inserts of pGL3-T and pGL3-G were confirmed by direct sequencing. Each vector of pGL3-T and pGL3-G had allele $G$ and allele $A$ at $-277 \mathrm{bp}$, respectively. The 6, 8, 10, 12 and 14 repeats of the pentanucleotide (CCTTT) region were obtained by PCR using forward (5'-ACCCCTGGAAGCCTACAACTGCAT-3') and reverse (5'-GCCACTGCACCCTAGCCTGTCTCA-3') primers. The PCR products were cloned into the upstream of the inserted NOS2 gene promoter in pGL3-T and pGL3-G. The resulting constructs were named pGL3-T6, pGL3-G6, pGL3-T8, pGL3-G8, pGL3-T10, pGL3-G10, pGL3-T12, pGL3-G12, pGL3-T14 and pGL3-G14, and contain $6,8,10,12$ and 14 repeats, respectively.
Human fibroblasts from three healthy individuals were cultured in Dulbecco's modified Eagle's medium (DMEM) with 10\% foetal bovine serum (FBS; Sigma, St. Louis, MO, USA). For transient transfections, fibroblasts were cultured in six-well plates with $3 \mathrm{ml}$ Opti-MEM (Invitrogen) containing $4 \mu \mathrm{g}$ DNA (pGL3 and phRL-TK vectors) and $12 \mu$ l Lipofectamine 2000 (Invitrogen). After 4 hours, $3 \mathrm{ml}$ DMEM with 20\% FBS in the presence or absence of recombinant interleukin-1 $\beta(10 \mathrm{ng} / \mathrm{ml}$; R\&D Systems) was added. The medium was changed after 16 hours to DMEM with 10\% FBS in the presence or absence of interleukin-1 $\beta$ (5 ng/mL). After an additional 24 hours of culture, the cells were washed twice using cold phosphate-buffered saline and were harvested. Firefly and Renilla luciferase activities were measured using the Dual-Glo Luciferase Assay System (Promega). Fibroblasts were cotransfected with a constitutively active Renilla luciferase vector (phRL-TK), and firefly luciferase activity was normalized by Renilla luciferase activity.

\section{Statistics}

Circulating ET- 1 and NO concentrations are given as mean \pm standard deviation, and data were compared using the Student's $t$ test. We assessed the significance of the $-277 \mathrm{~A} / \mathrm{G}$ and $-1026 \mathrm{G} / \mathrm{T}$ single nucleotide polymorphisms (SNPs) by the Fisher exact test. The relationship between the NO/ET-1 ratio and summed CCTTT repeat length was analyzed using linear regression analysis. An allelic distribution of the number of CCTTT repeats was compared using the Mann-Whitney $U$ test. $P<0.05$ was considered statistically significant. 

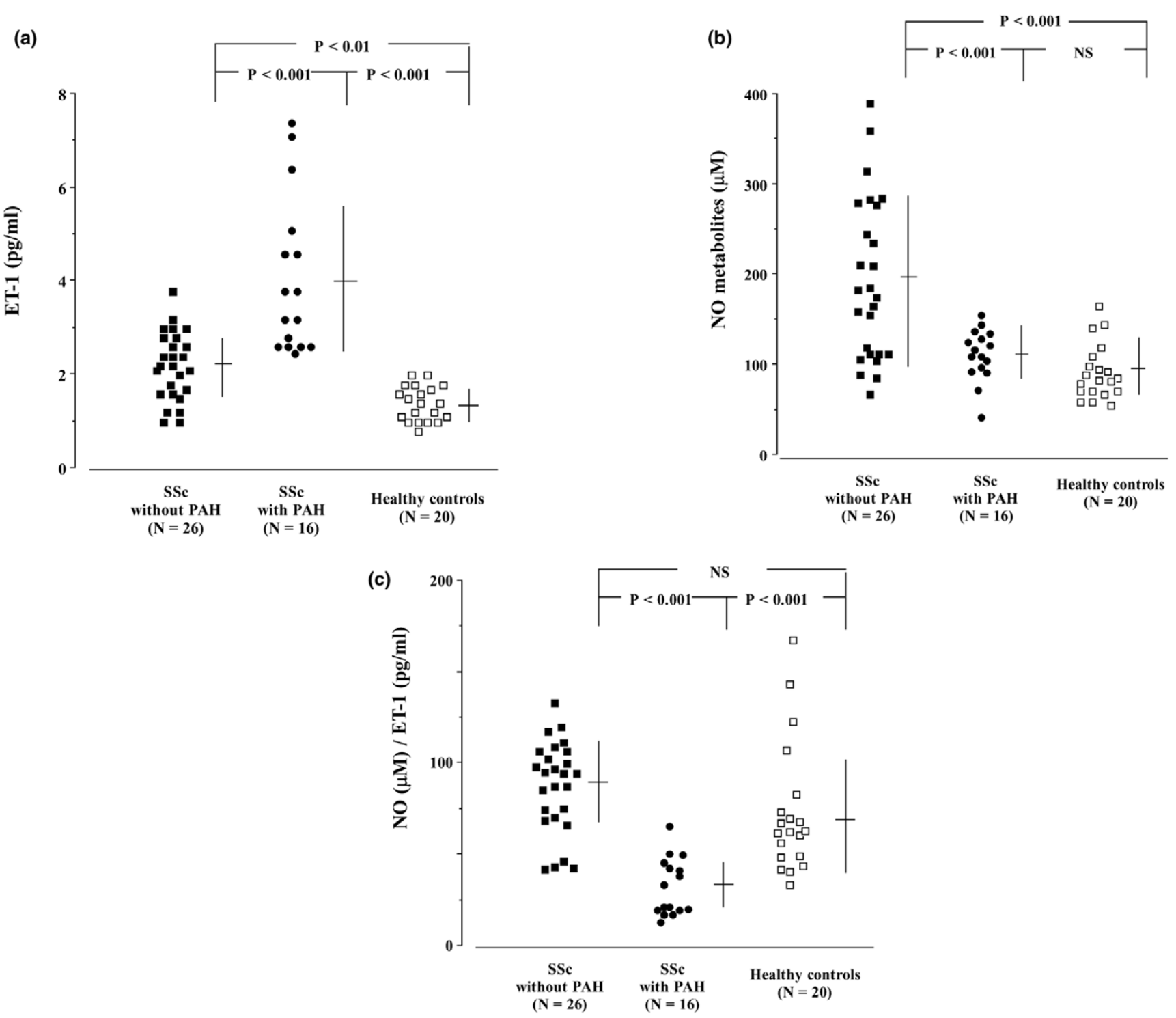

Circulating levels of ET-1 and NO. (a) Plasma levels of ET-1 were measured in patients with SSc with or without PAH. (b) Serum levels of NO metabolites were measured. (c) The ratios of NO/ET-1 are shown. Data are expressed as mean \pm standard deviation. ET, endothelin; NO, nitric oxide; NS, not significant; PAH, pulmonary arterial hypertension; SSc, systemic sclerosis.

\section{Results}

Circulating endothelin-1 and nitric oxide concentrations

Plasma ET-1 levels were significantly higher in each SSc group than in healthy control individuals $(1.4 \pm 0.4 \mathrm{pg} / \mathrm{ml})$, as shown in Figure 2a. Moreover, ET-1 levels in patients with both SSc and $\mathrm{PH}$ were significantly higher than in patients with SSc but not PAH $(4.1 \pm 1.7$ versus $2.2 \pm 0.8 \mathrm{pg} / \mathrm{ml} ; P<$ $0.001)$. In contrast, $\mathrm{NO}$ levels in patients with both SSc and $\mathrm{PAH}(114 \pm 28 \mu \mathrm{mol} / \mathrm{l})$ were similar to those in healthy control individuals (95 $\pm 30 \mu \mathrm{mol} / \mathrm{l})$, but $\mathrm{NO}$ levels in patients with SSc but not PAH (194 $\pm 89 \mu \mathrm{mol} / \mathrm{l})$ were significantly higher than in the other two groups (Figure $2 b$ ). The NO/ET-1 ratio was significantly lower in patients with both SSc and $\mathrm{PAH}$
$(32.6 \pm 15.7 ; n=16)$ than in patients with SSc but not PAH (87.8 $\pm 25.0 ; n=26)$ and healthy control individuals (73.6 \pm $35.7 ; n=20$ ), as shown in Figure 2c.

\section{Determination of single nucleotide polymorphisms in the NOS2 promoter region}

We genotyped the 78 patients with SSc and the 95 control individuals for the promoter region (-100 to $-1335 \mathrm{bp})$ of the NOS2 gene by direct DNA sequencing. We confirmed the presence of two previously reported SNPs at positions -277 and -1026 (Figure 3). The distribution of genotypes is shown in Table 1. The distribution of genotypes at -1026 and -277 was significantly different between patients with SSc who had 
NOS2 transcription start site

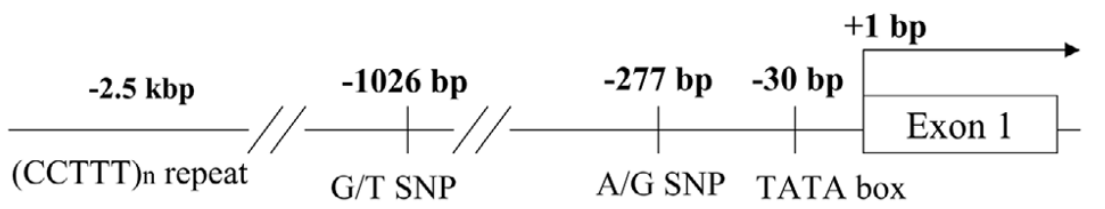

Polymorphisms of the $5^{\prime}$ flanking region of the human NOS2 gene. TATA sequence begins at position -30 bp from the transcription start site of exon 1. bp, base pairs; SNP, single nucleotide polymorphism.

$\mathrm{PAH}$ and those who did not have $\mathrm{PAH}$ (both $P=0.04$, by Fisher's exact test), but there was no difference between patients with SSc who did not have $\mathrm{PAH}$ and healthy control individuals in the distribution of genotypes at two SNPs. Between healthy control individuals and patients with both SSc and $\mathrm{PAH}$, there was a significant difference in the distribution of genetypes at $-1026(P=0.02)$; in contrast, there was no difference at $-277(P=0.053)$.

\section{Haplotype typing of the NOS2 promoter region}

We typed the haplotype of the gene, which consists of two SNPs at positions $-1,026$ and -277 . The two SNPs were found to be in linkage disequilibrium. We identified three haplotypes using genes from patients with SSc and healthy control individuals: GA, GG, and TG (Table 2). The frequency of haplotype GA was significantly higher in patients with both SSc and $\mathrm{PAH}$ than in patients with SSc but not $\mathrm{PAH}$ and in healthy individuals ( $P=0.001$ and $P=0.02$, respectively), as shown in Table 2.

\section{Distribution of variable numbers of tandem repeat in the NOS2 promoter region}

The 15 alleles found in the present study had 6-21 repeats, and the distribution was significantly different between patients with SSc and $\mathrm{PAH}$ and healthy control individuals $(P$ $<0.0001)$ and between patients with SSc with PAH and those with without PAH $(P<0.0001)$, as shown in Table 3. In contrast, there was no significant difference in distribution between patients with SSc but not PAH and healthy control individuals. If CCTTT repeat length strongly influences NOS2 transcription, then we would expect there to be a significant correlation between CCTTT repeat length and serum $\mathrm{NO}$ levels or NO/ET-1 ratios. We calculated the number of summed CCTTT repeats and then analyzed the correlation between that number and serum NO levels or NO/ET-1 ratios. As shown in Figure 4, there was a significant correlation between summed repeat length and both serum NO levels $(r=0.51, P$ $<0.01$; linear regression analysis) and NO/ET-1 ratios $(r=$ $0.83, P<0.0001)$ in all patients with SSc. However, in healthy control individuals we identified no significant correlation (data not shown).

\section{Effects of NOS2 polymorphisms on transcriptional activity of the gene}

To determine whether the polymorphisms of -277 SNP and 1,026 SNP and variable numbers of tandem repeat were associated with transcription of the NOS2 gene, we evaluated promoter activities using the series of NOS2 promoter-luciferase constructs (as described under Materials and method, above). As shown in Figure 5, NOS2 was almost transcriptionally silent in fibroblasts without stimuli. In contrast, transcription was induced in fibroblasts transfected with vectors, including promoter regions of the NOS2 gene, under stimulation by interleukin-1 $\beta$. The relative luciferase activities gradually increased with increasing number of CCTTT repeats in both alleles $G$ and $T$ at $-1,026$. In the case of the same number of CCTTT repeats, the relative luciferase activity was higher in vectors that included the promoter region with allele $\mathrm{T}$ at 1,026 than in vectors that included the promoter region with allele $\mathrm{G}$. These findings indicate that transcriptional activity of the NOS gene that includes $\mathrm{G}$ at $-1,026$ and a small number of tandem repeats was low.

\section{Discussion}

In the present study were found that concentrations of $\mathrm{NO}$ metabolites were not increased in patients with both SSc and $\mathrm{PAH}$, although plasma ET-1 levels were markedly elevated. Our previous report [21] indicates that serum levels of NO metabolites were significantly higher in patients with SSc than in healthy control individuals, especially in patients with a diffuse cutaneous type, active fibrosing alveolitis, or a short duration since onset. However, the population considered in that study did not include patients with $\mathrm{PAH}$, which could explain why the present findings are inconsistent with those of the previous report. Although a number of reports have been published concerning concentrations of ET-1 or NO in the circulation of patients with SSc [8,13-21], this report is the first to describe an imbalance in the NO/ET-1 ratio in patients with $\mathrm{PAH}$.

Over the past decade abnormalities in NO synthesis have been proposed as being important in the pathogenesis and development of pulmonary hypertension, especially primary pulmonary hypertension (PPH). Initially, immunohistochemical studies showed that pulmonary hypertension was associated 
Figure 4

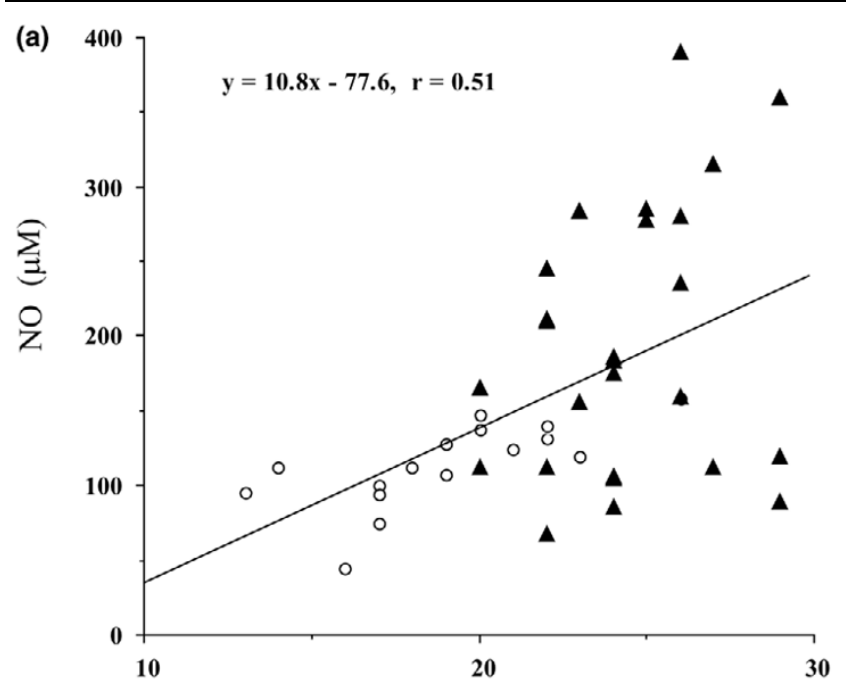

CCTTT summed repeat length

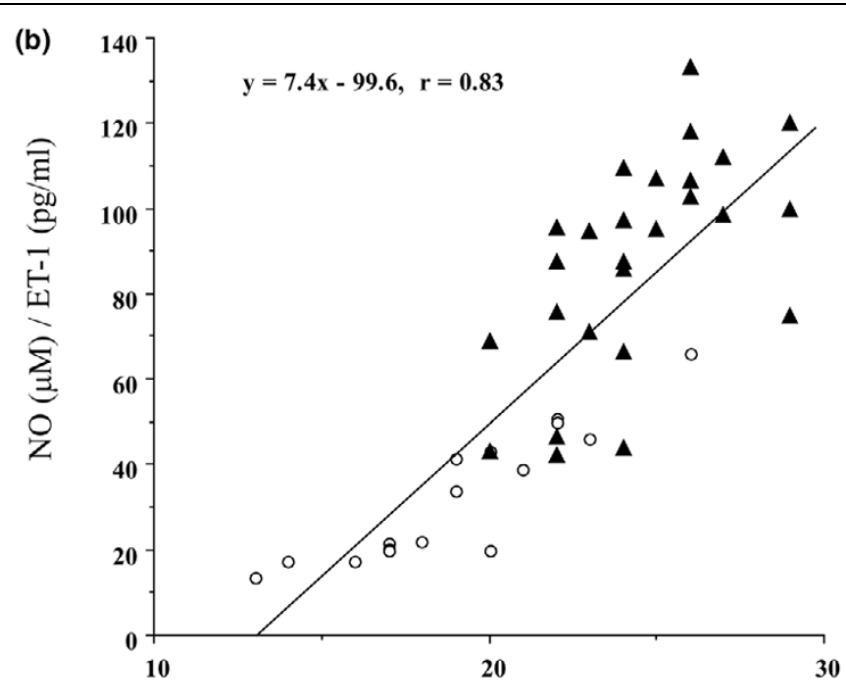

CCTTT summed repeat length

Relationship between NO levels or NO/ET-1 ratios and summed CCTTT repeat length. The association study between summed lengths of the CCTTT repeat and (a) serum NO levels and (b) NO/ET-1 ratios was performed in 16 patients with SSc with PAH (open circles) and 26 patients with SSc without PAH (black triangles). The results of linear regression analysis of the data are represented by the solid line. Serum NO levels and NO/ET-1 ratios were significantly correlated with summed CCTTT repeat lengths $(r=0.51, P<0.01$; and $r=0.83, P<0.0001$, respectively). ET, endothelin; NO, nitric oxide; $\mathrm{PAH}$, pulmonary arterial hypertension; SSc, systemic sclerosis.

\section{Figure 5}

(a)

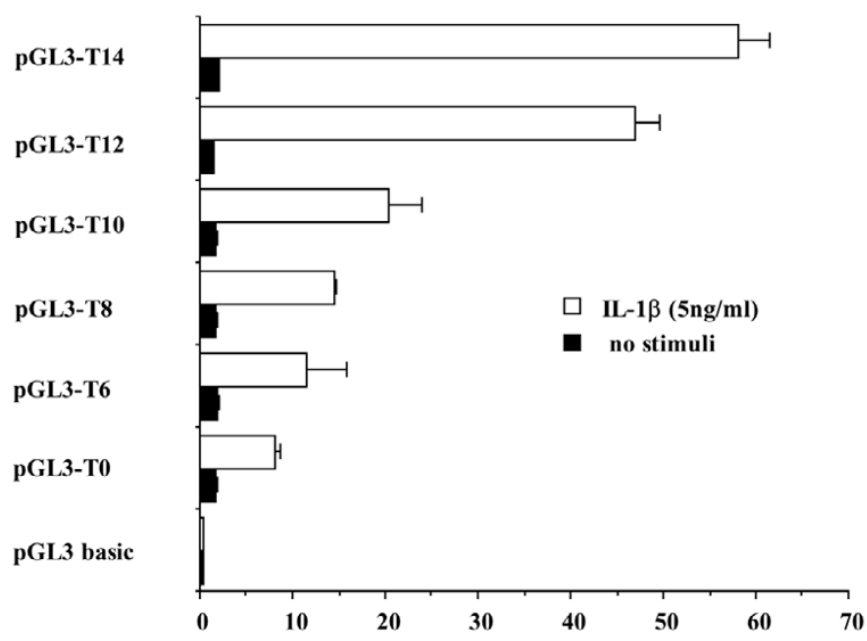

Relative Firefly/Renilla luciferase activity (b)

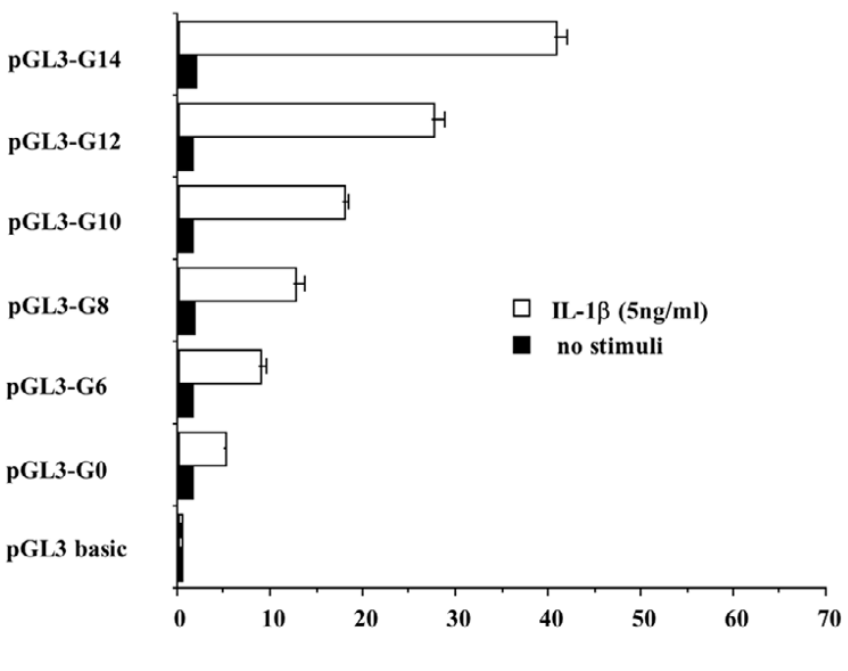

Relative Firefly/Renilla luciferase activity

Luciferase reporter assay of the NOS2 promoter with gene polymorphisms. The (a) pGL3-T vectors and (b) pGL3-G vectors were cloned by the NOS2 promoter region, including alleles T and G of the single nucleotide polymorphism at $-1026 \mathrm{bp}$. In the series of pGL3-T or pGL3-G vectors, the $6,8,10,12$ and 14 repeats of the CCTTT region were cloned upstream of the inserted NOS2 promoter in pGL3-T or pGL3-G. bp, base pairs; IL, interleukin.

with diminished expression of NOS-3 [37]. However, other studies found increase in expression of NOS-3 in patients with pulmonary hypertension and in animal models of pulmonary hypertension $[38,39]$. Despite these contradictory findings, it has been reported that NO levels in blood and the lungs were precisely decreased in patients with $\mathrm{PPH}$ and collagen disease related $\mathrm{PAH}$ [8-12]. Furthermore, it was determined that NOS-dependent endogenous NO synthesis was decreased in patients with $\mathrm{PPH}$, which suggests that NOS activity may be diminished in patients with PPH [40]. Lung inflammation lead- 
Table 3

\begin{tabular}{|c|c|c|c|}
\hline \multirow[t]{2}{*}{ Allele } & \multicolumn{2}{|c|}{ SSc patients } & \multirow{2}{*}{$\begin{array}{l}\text { Healthy } \\
\text { controls }\end{array}$} \\
\hline & With PAH & Without PAH & \\
\hline 6 & 2 & 0 & 0 \\
\hline 7 & 2 & 0 & 0 \\
\hline 8 & 8 & 0 & 4 \\
\hline 9 & 6 & 4 & 8 \\
\hline 10 & 10 & 11 & 19 \\
\hline 11 & 5 & 16 & 25 \\
\hline 12 & 6 & 29 & 42 \\
\hline 13 & 0 & 22 & 32 \\
\hline 14 & 1 & 14 & 29 \\
\hline 15 & 0 & 7 & 13 \\
\hline 16 & 0 & 4 & 13 \\
\hline 17 & 0 & 4 & 4 \\
\hline 18 & 0 & 2 & 1 \\
\hline 19 & 0 & 2 & 0 \\
\hline 20 & 0 & 0 & 0 \\
\hline 21 & 0 & 1 & 0 \\
\hline
\end{tabular}

$P<0.0001$ for patients with both SSc and PAH compared with healthy control subjects by the Mann-Whitney $U$ test. $P<0.0001$ for patients with both SSc and PAH compared with patients with SSc but not PAH by the Mann-Whitney $U$ test. $P A H$, pulmonary arterial hypertension; SSc, systemic sclerosis.

ing to increased levels of cytokines and oxidants may contribute to the development of both PPH and SSc-related PAH [41]. In the presence of increased levels of inflammatory mediators, NOS activity may be dependent on production of NOS2 , which is distinct from NOS-3 (the endothelial form of NOS) because NOS-2 is inducible by inflammatory mediators, and induced levels are much greater than levels of constitutive NOS-3 production. Peripheral mononuclear cells and lesional fibroblasts are capable of aberrant production of inflammatory cytokines in patients with SSc [42-44]. These cytokines may be involved not only in ET-1 synthesis by endothelial cells and fibroblasts but also in induction of NOS-2. Also, excessive production of ET-1 can mediate NOS-2 production through ET receptor $B$ [45]. Although evidence based on those biological properties may promote speculation that levels of ET-1 correlate with levels of $\mathrm{NO}$ in the circulation, NO metabolite levels were within normal range in patients with both SSc and $\mathrm{PAH}$ patients whose serum contained much ET-1. We hypothesize that this discrepancy may be explained by reduced NOS-2 production resulting from polymorphisms in the NOS2 gene.

As a result of sequencing the promoter region of the NOS2 gene from -100 to $-1,335$, we were able to confirm the pres- ence of two SNPs, consistent with previous reports [46]. In the present study, allele $A$ at -277 SNP, allele $G$ at -1,026 SNP and shorter forms of the CCTTT repeat were associated with susceptibility to PAH combined with SSc. The number of CCTTT repeats was previously reported to influence transcription of the NOS2 gene [47]. However, studies of variable numbers of tandem repeat both in vitro and in vivo have yielded conflicting results [48]. To confirm whether those polymorphisms affect transcription of the NOS2 gene in fibroblasts, we constructed a series of luciferase reporter vectors cloned by various numbers of CCTTT combined with the promoter region of the NOS2 gene from +58 to $-1,557$, which included two kinds of haplotype.

Transcriptional activity was lowest in the NOS2 gene containing the six repeats of CCTTT and haplotype GA, which suggests that transcription of the NOS2 gene might be little induced by interleukin-1 $\beta$ in patients with SSc-related $\mathrm{PAH}$.

Irrespective of whether patients with SSc had PAH, CCTTT repeat length was well correlated with NO/ET-1 ratio. With regard to the relationship between CCTTT repeat length and serum NO levels, we found no significant difference among SSc patients without $\mathrm{PAH}$, although there were significant differences among all SSc patients and among patients with both SSc and PAH (data not shown). In the setting of aberrant production of ET-1 or cytokines, NO synthesis via NOS-2 induction may be dependent on NOS2 gene polymorphisms. In healthy control individuals, who had no vascular damage, inflammation, or autoimmune disorders, there was no association between CCTTT repeat length and either serum $\mathrm{NO}$ levels or NO/ET-1 ratios (data not shown). Because NOS-2 induction is well controlled by ET-1 and cytokines, distinct from NOS-3, which is constitutively produced, it has been suggested that the CCTTT repeat length is more significantly correlated with NO/ET-1 ratios than with serum NO levels. Our observations support the concept that the NOS2 gene polymorphism is a crucial factor in NO synthesis under conditions of vascular damage and chronic inflammation, as well as $\mathrm{PAH}$.

It is not possible to determine whether SSc patients without $\mathrm{PAH}$ will suffer this complication in the future, and this is a limitation of the present study. The patients enrolled in the study are from a prospective cohort at our institution, and they have been observed for clinical complications, including $\mathrm{PAH}$, in the follow-up clinic. None of the 58 patients with SSc but not PAH has yet been diagnosed with $\mathrm{PAH}$ (mean duration of observation: 45 months).

\section{Conclusion}

$\mathrm{NO}$ is a key factor in generating $\mathrm{PAH}$ complicated by SSc, and the decrease in NO synthesis might be attributable to reduced NOS-2 production, which is dependent on NOS2 gene polymorphisms. Therapeutic options for $\mathrm{PAH}$ occurring as a complication of SSc are limited; however, it is not usually the first 
complication, and it develops several years after SSc is diagnosed. We believe that the development of means to predict the occurrence of PAH related to SSc, and hence prevent this complication, would be a great step forward. Although prospective, longitudinal studies are needed, we propose that patients with SSc who exhibit an imbalance between NO and ET-1 production and who have a short length of CCTTT repeat of the NOS2 gene can be treated with a phosphodiesterase type 5 inhibitor before the occurrence of $\mathrm{PAH}$.

\section{Competing interests}

The authors declare that they have no competing interests.

\section{Authors' contributions}

YK designed the study, recruited the patients and drafted the manuscript. AT was responsible for the recruitment and classification of the patients, and determined genotypes of NOS2. $\mathrm{MH}$ participated in coordination of the study. MK determined the phenotype of polymorphisms. TS and YK participated in coordination of the study. JO, HK and $\mathrm{MO}$ were responsible for the recruitment and classification of patients and healthy volunteers. NK participated in the design and coordination of the study. All authors read and approved the final manuscript.

\section{Acknowledgements}

This study was supported in part by the Japanese Ministry of Health, Labour and Welfare grant (the research for Mixed Connective Tissue Disease) and the Research for the Future Program of the Japan Society for the Promotion of Science.

\section{References}

1. Varga J, Korn JH: Pathogenesis. Emphasis on human data. In Systemic Sclerosis 2nd edition. Edited by: Clements PJ, Furst DE. Philadelphia: Williams \& Wilkins; 2004:63-97.

2. Coghlan JG, Mukerjee D: The heart and pulmonary vasculature in scleroderma: clinical features and pathobiology. Curr Opin Rheumatol 2001, 13:495-499.

3. Kawut SM, Taichman DB, Archer-Chicko CL, Palevsky HI, Kimmel SE: Hemodynamics and survival in patients with pulmonary arterial hypertension related to systemic sclerosis. Chest 2003, 123:344-350.

4. Cooke JP: A novel mechanism for pulmonary arterial hypertension. Circulation 2003, 108:1420-1421.

5. Stewart DJ, Levy RD, Cernacek P, Langleben D: Increased plasma endothelin-1 in pulmonary hypertension: marker or mediator of disease? Ann Intern Med 1991, 114:464-469.

6. Giaid A, Yanagisawa M, Langleben D, Michel RP, Levy R, Shennib $\mathrm{H}$, Kimura S, Masaki T, Duguid WP, Stewart DJ: Expression of endothelin-1 in the lungs of patients with pulmonary hypertension. N Engl J Med 1993, 328:1732-1739.

7. Rubens C, Ewert R, Halank M, Wensel R, Orzechowski HD, Schultheiss HP, Hoeffken G: Big endothelin-1 and endothelin-1 plasma levels are correlated with the severity of primary pulmonary hypertension. Chest 2001, 120:1562-1569.

8. Kharitonov SA, Cailes JB, Black CM, du Bois RM, Barnes PJ: Decreased nitric oxide in the exhaled air of patients with systemic sclerosis with pulmonary hypertension. Thorax 1997, 52:1051-1055.

9. Rolla G, Colagrande P, Scappaticci E, Chiavassa G, Dutto L, Cannizzo S, Bucca C, Morello M, Bergerone S, Bardini D, et al.: Exhaled nitric oxide in systemic sclerosis: relationships with lung involvement and pulmonary hypertension. J Rheumatol 2000, 27:1693-1698.

10. Kaneko FT, Arroliga AC, Dweik RA, Comhair SA, Laskowski D, Oppedisano R, Thomassen MJ, Erzurum SC: Biochemical reac- tion products of nitric oxide as quantitative markers of primary pulmonary hypertension. Am J Respir Crit Care Med 1998, 158:917-923.

11. Cella G, Bellotto F, Tona F, Sbarai A, Mazzaro G, Motta G, Fareed $\mathrm{J}$ : Plasma markers of endothelial dysfunction in pulmonary hypertension. Chest 2001, 120:1226-1230.

12. Machado RF, Londhe Nerkar MV, Dweik RA, Hammel J, Janocha A, Pyle J, Laskowski D, Jennings C, Arroliga AC, Erzurum SC: Nitric oxide and pulmonary arterial pressures in pulmonary hypertension. Free Radic Biol Med 2004, 37:1010-1017.

13. Morelli S, Ferri C, Polettini E, Bellini C, Gualdi GF, Pittoni V, Valesini G, Santucci A: Plasma endothelin-1 levels, pulmonary hypertension, and lung fibrosis in patients with systemic sclerosis. Am J Med 1995, 99:255-260.

14. Yamane K, Miyauchi T, Suzuki N, Yuhara T, Akama T, Suzuki H, Kashiwagi H: Significance of plasma endothelin-1 levels in patients with systemic sclerosis. I Rheumatol 1992, 19:1566-1571.

15. Yamamoto T, Katayama I, Nishioka K: Nitric oxide production and inducible nitric oxide synthase expression in systemic sclerosis. J Rheumatol 1998, 25:314-317.

16. Andersen GN, Caidahl K, Kazzam E, Petersson AS, Waldenstrom A, Mincheva-Nilsson L, Rantapaa-Dahlqvist S: Correlation between increased nitric oxide production and markers of endothelial activation in systemic sclerosis: findings with the soluble adhesion molecules E-selectin, intercellular adhesion molecule 1, and vascular cell adhesion molecule 1. Arthritis Rheum 2000, 43:1085-1093.

17. Cotton SA, Herrick AL, Jayson MI, Freemont AJ: Endothelial expression of nitric oxide synthases and nitrotyrosine in systemic sclerosis skin. J Pathol 1999, 189:273-278.

18. Sud A, Khullar M, Wanchu A, Bambery P: Increased nitric oxide production in patients with systemic sclerosis. Nitric Oxide 2000, 4:615-619.

19. Kahaleh BM, Pan-Sheng F, Cerinic MM, Stefanovic Racic M, Ignarro L: Study of endothelial dependent relaxation in scleroderma. Arthritis Rheum 1993, 36:S180.

20. Allanore $Y$, Borderie $D$, Hilliquin $P$, Hernvann $A$, Levacher $M$ Lemarechal H, Ekindjian OG, Kahan A: Low levels of nitric oxide (NO) in systemic sclerosis: inducible NO synthase production is decreased in cultured peripheral blood monocyte/macrophage cells. Rheumatology 2001, 40:1089-1096.

21. Takagi $K$, Kawaguchi $Y$, Hara M, Sugiura T, Harigai M, Kamatani N: Serum nitric oxide (NO) levels in systemic sclerosis patients: correlation between NO levels and clinical features. Clin Exp Immunol 2003, 134:538-544.

22. Palmer RM, Ashton DS, Moncada S: Vascular endothelial cells synthesize nitric oxide from L-arginine. Nature 1988, 333:664-666.

23. Forstermann U, Gath I, Schwarz P, Closs El, Kleinert H: Isoforms of nitric oxide synthase. Properties, cellular distribution and expressional control. Biochem Pharmacol 1995, 50:1321-1332.

24. Nathan $\mathrm{C}, \mathrm{Xie} \mathrm{OW}$ : Regulation of biosynthesis of nitric oxide. $J$ Biol Chem 1994, 269:13725-13728.

25. Channick RN, Simonneau G, Sitbon O, Robbins IM, Frost A, Tapson VF, Badesch DB, Roux S, Rainisio M, Bodin F, Rubin LJ: Effects of the dual endothelin-receptor antagonist bosentan in patients with pulmonary hypertension: a randomized placebocontrolled study. Lancet 2001, 358:1119-1123.

26. Rubin $\amalg$, Badesch DB, Barst RJ, Galie N, Black CM, Keogh AK, Pulido T, Frost A, Roux S, Leconte I, et al:: Bosentan in patients with pulmonary arterial hypertension: a randomized, placebo controlled, multicenter study. N Engl J Med 2002, 346:896-903.

27. Mehta S: Sildenafil for pulmonary arterial hypertension: exciting, but protection required. Chest 2003, 123:989-992.

28. McMullan DM, Bekker JM, Johengen MJ, Hendricks-Munoz K, Gerrets R, Black SM, Fineman JR: Inhaled nitric oxide-induced rebound pulmonary hypertension: a role for endothelin-1. Am J Physiol Heart Circ Physiol 2001, 280:H777-H785.

29. Ghofrani HA, Pepke-Zaba J, Barbera JA, Channick R, Keogh AM, Gomez-Sanchez MA, Kneussl M, Grimminger F: Nitric oxide pathway and phosphodiesterase inhibitors in pulmonary arterial hypertension. J Am Coll Cardiol 2004, 43:68S-72S.

30. Johannesen J, Tarnow L, Parving H-H, Nerup J, Pociot F: CCTTTrepeat polymorphism in the human NOS2-promoter confers 
low risk of diabetic nephropathy in type 1 diabetic patients. Diabetes Care 2000, 23:560-562.

31. Konno S, Hizawa N, Yamaguchi E, Jinushi E, Nishimura M: (CCTTT)n repeat polymorphism in the NOS2 gene promoter is associated with atopy. J Allergy 2001, 108:810-814.

32. Hobbs MR, Udhayakumar V, Levesque MC, Booth J, Roberts JM, Tkachuk A: A new NOS2 promoter polymorphism associated with increased nitric oxide production and protection from severe malaria in Tanzanian and Kenyan children. Lancet 2002, 360:1468-1475.

33. Subcommittee for Scleroderma Criteria of the American Rheumatism Association Diagnostic and Therapeutic Criteria Committee: Preliminary criteria for the classification of systemic sclerosis (scleroderma). Arthritis Rheum 1980, 23:581-590.

34. LeRoy EC, Black C, Fleischmajer R, Jablonska S, Krieg T, Medsger TA Jr, Rowell N, Wollheim F: Scleroderma (systemic sclerosis): classification subsets and pathogenesis. J Rheumatol 1988, 15:202-205.

35. Rich S, Dantzker DR, Ayres SM, Bergofsky EH, Brundage BH, Detre KM, Fishman AP, Goldring RM, Groves BM, Koerner SK, et al:: Primary pulmonary hypertension. A national prospective study. Ann Intern Med 1987, 107:216-223.

36. Ito $T$, Inoue $E$, Kamatani N: Association test algorithm between a qualitative phenotype and a haplotype or haplotype set using simultaneous estimation of haplotype frequencies, diplotype configurations and diplotype-based penetrances. Genetics 2004, 168:2339-2348.

37. Giaid A, Saleh D: Reduced expression of endothelial nitric oxide synthase in the lungs of patients with pulmonary hypertension. N Engl J Med 1995, 333:214-221.

38. Xue C, Johns RA: Endothelial nitric oxide synthase in the lungs of patients with pulmonary hypertension. N Engl J Med 1995, 333:1642-1644.

39. Xue C, Johns RA: Upregulation of nitric oxide synthase correlates temporally with onset of pulmonary vascular remodeling in the hypoxic rat. Hypertension 1996, 28:743-753.

40. Demoncheaux EAG, Higenbottam TW, Kiely DG, Wong J-M, Wharton S, Varcoe R, Siddons T, Spivey AC, Hall K, Gize AP: Decreased whole body endogenous nitric oxide production in patients with primary pulmonary hypertension. J Vasc Res 2005, 42:133-136.

41. Humbert M, Monti G, Brenot F, Sitbon O, Portier A, GrangeotKeros L, Duroux $P$, Galanaud P, Simonneau G, Emilie D: Increased interleukin-1 and interleukin-6 serum concentrations in severe primary pulmonary hypertension. Am J Respir Crit Care Med 1995, 151:1628-1631.

42. Kadono T, Kikuchi K, Ihn H, Takehara K, Tamaki K: Increased production of interleukin 6 and interleukin 8 in scleroderma fibroblasts. J Rheumatol 1998, 25:296-301.

43. Kawaguchi Y, Suzuki K, Hara M, Hidaka T, Ishizuka T, Kawagoe M, Nakamura $\mathrm{H}$ : Increased endothelin-1 production in fibroblasts derived from patients with systemic sclerosis. Ann Rheum Dis 1994, 53:506-510.

44. Kawaguchi $Y: I L-1 \beta$ gene expression and protein production by fibroblasts from patients with systemic sclerosis. Clin Exp Immunol 1994, 97:445-450.

45. Gay G, Webb DJ: The endothelin system and its potential as a therapeutic target in cardiovascular disease. Pharmacol Ther 1996, 72:109-148.

46. Burgner D, Usen S, Rockett $K$, Jallow $M$, Ackerman $H$, Cervino A, Pinder M, Kwiatkowski DP: Nucleotide and haplotypic diversity of the NOS2A promoter region and its relationship to cerebral malaria. Hum Genet 2003, 112:379-386.

47. Warpeha KM, Xu W, Liu L, Charles IG, Patterson CC, Ah-Fat F, Harding S, Hart PM, Chakravarthy U, Hughes AE: Genotyping and functional analysis of a polymorphic (CCTTT)n repeat of NOS2A in diabetic retinopathy. FASEB J 1999, 13:1825-1832.

48. Boutlis CS, Hobbs MR, Marsh RL, Misukonis MA, Tkachuk AN, Lagog M, Booth J, Granger DL, Bockarie MJ, Mgone CS, et al.: Inducible nitric oxide synthase (NOS) promoter CCTTT repeat polymorphism: relationship to in vivo nitric oxide production/ NOS activity in an asymptomatic malaria-endemic population. Am J Trop Med Hyg 2003, 69:569-573. 